\title{
On the implications of non-translation in Portuguese advertising: names in cosmetic products as a case in point
}

\author{
Sandra Gonçalves Tuna \& Elsa Simões Lucas Freitas \\ Universidade Fernando Pessoa \\ E-mail: stuna@ufp.edu.pt / esimoes@ufp.edu.pt
}

\begin{abstract}
The issue of advertising translation inevitably raises that of international marketing. One of the preliminary assumptions underlying product internationalization seems to be the widespread belief in significant similarities between people from different world regions and cultures, which has led to a fairly high degree of standardization in many product features. This is the case of many cosmetic products, sold worldwide with identical advertising strategies. Despite divergent approaches to international campaigns adopted by different cultures/countries,

translation. Whether translation includes pictorial or textual elements, or both, it also seems to depend on cultural issues. In Portugal, international campaigns of cosmetic products seldom involve profound incursions into the advertisement layout. Except for the copy text, there are several elements that remain unscathed in Portuguese adverts: overall structure, pictures and names. The present paper will address these issues, trying to infer some of the implications that this translational option might bring to cosmetic advertising.
\end{abstract}

Keywords: Translation; international advertising; names; cosmetics.

\section{Introduction}

$\mathrm{T}^{\mathrm{T}}$ is barely surprising that product names should play a significant role in marketing strategies and that they are therefore object of careful consideration by marketers, sellers and manufacturers. Regardless of names' semantic properties, and their relationship with the nature or purpose of a given product, names on the label will identify a given good, the brand, and will constitute a distinctive feature relative to analogous products or brands. This partly explains why companies often dedicate a significant amount of their time, effort 
and budget to finding the right name for a brand or a product, eventually resorting to naming specialist firms (Hammel, 1997, pp. 1-2). Naming and branding specialists regard this stage as a crucial one and claim that there are several factors underlying the assessment of a good name: 'difference, meaning the name must differentiate the product, relevance and customer engagement' (Birkner, 2001, p.6).

Today, in an internationally-oriented market, products frequently cross borders and all the factors and implications involved in the choice of a product/brand name become more complex, and one of the stages of the marketing process will definitely have to consider whether the product/brand name will be maintained, changed, translated or adapted in some way. This decision will have consequences for brands, from aspects related to brand image and coherence to budgetary conditions, and will also be influenced by the target culture(s) system(s), as it is ultimately the host culture that will determine the success of any marketing decision.

The present study will focus on the strategy adopted by cosmetics brands regarding product names, as these are products especially amenable to internationalization, and have long been exporting products. While it will consider the translational options used for the Portuguese market, examples from other cultures will be taken into account for comparative purposes.

\section{On the nature of advertising names}

Louis Goossens (1985) analyses advertising names by looking at different dimensions of meaning, namely 'reference' - the reality to which the name refers - and 'sense' - the semantic meaning. He also considers the 'extension' of names, the class of things to which the name applies, as well as its 'intension', which refers to the essential properties related to the term. He further argues that product names, like other proper names, are primarily referential, but, unlike other proper names, they are associated with a series of products belonging to a given product type. Therefore, in terms of extension, a product name may refer to a series of entities, and, as far as intension is concerned, the product name 'is the sum of properties shared by all instantiations of $\mathrm{P}$ [product name] that is to be taken as its intension' (1985, p.99). Within this framework, Clarins Bright Plus, for example, refers to all creams advertised (and sold) under that name, which means that its extension comprehends the 
On the implications of non-translation in Portuguese advertising: names in cosmetic products as a case in point

product range bearing that name, namely exfoliators, day/ night creams and masks, and its intension concerns the properties associated with this range of products.

As far as the 'sense' of the product name is concerned, which is the dimension of meaning that can be particularly problematic when advertisements cross linguistic boundaries, Goossens considers two possibilities: descriptive names, which directly point to the product type, and names which, despite using ordinary words, do not rely on their descriptive character, but on the associative meaning, which is expected to invest the product with a positive image. Cosmetic names, though often descriptive, also seem to benefit from associative meaning as, besides the meaning implied by the carefully chosen words that compose the name, they draw significantly on the meanings generated by the terms used. And, in addition to the dimensions suggested by Goossens, the connotations and associations of cosmetic names are largely dependent on the image that a particular brand already has and on the image conveyed by the specific advertising of the product:

Meaning of this associative type is often exploited to the full by advertisers. Much of the suggestive (and manipulative) power of advertisements may reside in the fact that the boundary line between sense and non-constitutive associative meaning is not always easy to draw. (p.102)

Dyer also emphasises the associative and connotational dimensions of product names, explaining that, when naming a product, advertisers try to 'invest it with particular meanings and associations. The name should do more than just label or identify the product; it should bring flattering associations to mind, associations which help to sell it' (1982, p.141). While analysing the functioning of name attribution to luxury products such as perfumes (and, by extension, to high-priced cosmetic products), Cook also points out the advantages of ambiguity in such naming: 'Perhaps the most effective names are those which arouse many different connotations, allowing the product to appeal to incompatible desires within one person, or to different types of people.' (1992, p. 106) 


\section{On the nature of names in cosmetic products}

Cosmetic names often consist of a tripartite structure: the brand name, the product line, and the product name or function: Shiseido - Vital Perfection Balancing Softener. A bipartite structure, consisting of the brand name and the product name, is also common: Dior - Capture Essentiel. In such cases, the function or purpose of the product is sometimes provided in smaller print, as well, which means that, in the end, the structure is essentially tripartite in terms of information. There is an obvious descriptive tone, as at least one part of the name indicates the very nature and/or function of the product they denominate. According to Goossens's model (1985), described above, the descriptive dimension of cosmetic products' names is fundamental, for they normally consist of common nouns, whose ordinary meaning (or denotational meaning) is expected to be taken into account, with no detriment to the connotations they may benefit from. On the contrary, the non-constitutive associative meaning plays a part in names that have a clear advertising function:

$$
\begin{aligned}
& \text { Clinique - Anti-Blemish Solutions - Clarifying Lotion } \\
& \text { Clinique - Anti-Blemish Solutions - Clearing Moisturiser } \\
& \text { Clinique - Redness Solutions - Daily Relief Cream } \\
& \text { Clinique - Redness Solutions - Soothing Cleanser } \\
& \text { Clinique - Redness Solutions - Daily Protective Base } \\
& \text { Shiseido - Benefiance WrinkleResist - Extra Creamy Cleansing Foam } \\
& \text { Shiseido - Benefiance WrinkleResist - Balancing Softener } \\
& \text { Yes to Tomatoes - Truly Terrific - Body Butter } \\
& \text { Christian Dior - Deep Radiance - Exfoliating Cream } \\
& \text { Clarins - Youthful Vitality - Multi-Active Night Lotion }
\end{aligned}
$$

We could be led to believe that such descriptive names would occur more often in skincare products, as they clearly need to indicate the specific function(s) and target group or skin/hair types they are aimed at, but there are plenty of examples from makeup products as well:

Shiseido - Translucent Loose Powder

Shiseido Luminizing Lip Gloss 
On the implications of non-translation in Portuguese advertising: names in cosmetic products as a case in point

\section{Shiseido Pore Smoothing Corrector}

Helena Rubinstein - Wanted Eyes - Perfect Color Blend Eyeshadow

Helena Rubinstein - Illumination - Natural Radiance Reviving Loose Powder

Indeed, even acknowledging the substantial meaning potential of cosmetics names, as defended by Merskin in a thorough analysis of lipstick names 'By using specific linguistic signs and symbols, lipstick names confer attitude, behavior, and/or access to a less fattening indulgence' (2007, p. 598), - It is still clear, in the results this author provides (597) that a considerable part of names $(20 \%)$ relate to product colour, thus providing a descriptive feature.

More than just trying to create a mood or image, the names provided are closely connected with the products' properties and functions. Names carry a characteristic of the product and the advertising promise. This means that the information provided by the product name displayed in advertisements may actually bring about changes in the audience's perception of the product, resulting in either a favourable attitude - grabbing their attention - or, a negative one, causing them to regard the product as unsuitable for their specific needs. In either case, this kind of information seems to be significant in terms of audience response, as it provides criteria for the selection of the product involved.

\section{On the translation of product names}

It seems rather evident that names play an important role in the advertising strategy, since the latter frequently evolves around the motto provided by the product name. Often, visuals, including typographical features, headlines and copy are built around the meanings - allusions, associations and connotations - suggested by cosmetic names, which may also inspire other marketing elements, including the packaging. The name works as a kind of overall theme, from which the advertising concept and message develop: $n$ Biotherm Aquasource advertisement, for example, as the name suggests, the main advertising promise is deep hydration. The light green skin cream jar is thus depicted in deep water, releasing air bubbles, with a bluish background. The text reinforces this watery scenario: 
Now Hydration goes deep. New Formula Aquasource. With thermal plankton cellular water. Paraben Free. Get fresh radiant skin all day long. The same detectable texture and scent now hydrates deeper than ever before!

Likewise, an advert for a Clinique foundation - Dewy Smooth, which promises an 'All day dew' (title), uses a picture of the product jar leaning against dewy deep green grass, where dew drops are foregrounded.

The prodigal semiotic potential of names becomes ever more visible when these cosmetics are exported to different cultures and languages, as translation, adaptation or alteration will directly impend on the desired meanings and associations for a given name. Both marketers and translators recognize the challenge and struggle with such challenge. International brands present different approaches: some provide translations, an option that is not so common in cosmetic products, others provide parallel translations and others use a standardized strategy.

Guidère (2000, p. 93) questions the translatability of advertising names, given their strong connotative value and culture-bound nature, since their effectiveness depends on the audience's shared knowledge to establish the desired associations. He discusses three translation strategies adopted to deal with product names in international marketing: transplantation, transliteration and transmutation. Of the three procedures suggested, the one that is used in Portuguese cosmetic marketing is 'transplantation', which implies the transfer of the product name without any change, in the original language. According to this author, the latter strategy is used by leading brands, which have reached a world-wide status that grants them recognition. This may be partly the case in Portugal if we consider brand names alone. Product names, however, need to be handled differently since they commonly derive from common names which would be translatable most of the times. Guidère claims that even in this case it would not be easy to find equivalents that would preserve a comparable connotative value in the target language, and that the naming systems are inescapably different from language to language (2000, p. 94-95). His view seems to suggest that there would probably be a loss of illocutionary force if names were translated. While these factors may eventually influence the strategy of non-translation, it seems that advertisers are more likely to be moved by marketing reasons, since, in addition to economic advantages asso- 
On the implications of non-translation in Portuguese advertising: names in cosmetic products as a case in point

ciated with standardization of names, their preservation also increases brand consistency (Yeshin, 2006, pp. 421-422).

Identical strategies used in overseas countries, namely in East Asian countries, such as China, seem to corroborate Yeshin's point of view, as a study conducted by Chang (2008) illustrates by examining the effectiveness of adopting a global look in the Asian market. In this study, in addition to displaying Western models in advertisements aimed at East-Asian audiences, marketers employ foreign, namely, English brand names to emphasise the product's or brand's global character. This is a strategy used both by multinationals, with standardization purposes, and by local marketers who wish to endow their brands/products with global properties and style (2008, pp. 200-202).

\section{Cosmetic names in translation}

The names of cosmetic products, like many other products which are marketed at an international level, usually remain untranslated in Portuguese. As mentioned above, 'transplantation' is the most frequent translational approach. This option seems to be motivated by the reasons discussed for other international products: in addition to the fact that most cosmetic adverts belong to long-established hegemonic brands, as well as the economic advantages of standardization, cosmetic names in other languages may also gain from the association with their country of origin or the language used. Also, some names may be easily understood by the Portuguese audience due to phonetic or spelling similarities:

\begin{tabular}{|l|l|}
\hline Estée Lauder Revelation & Revelacão \\
\hline Estée Lauder Perfectionist & Perfeccionista \\
\hline Estée Lauder Idealist & Idealista \\
\hline Estée Lauder Verité & Verdade \\
\hline Helena Rubinstein Illumination & Iluminacão \\
\hline Lancôme Adaptîve & Adaptável \\
\hline
\end{tabular}

On the other hand, the frequently functional and descriptive nature of cosmetics names, in addition to their prominent position in advertising pictures, may raise relevant translational and language issues. 
Cosmetics advertising relies increasingly more on pictures, which often depict the packaging in close-up, making names stand out significantly. Thus, it appears that by leaving these elements untranslated, Portuguese versions may become less accessible to the readers, who may fail to fully understand the properties or the specific type of product advertised. Once again, it seems important to consider the non-arbitrary nature of cosmetics names, which, as expected, are carefully chosen so as to bring positive associations to mind in addition to being normally meaningful and descriptive. As claimed by Dyer (1982, p.141), 'names given to cosmetics and other beauty products frequently recall images of beauty, cleanliness, sophistication and naturalness'. Besides, the pseudo-scientific discourse, so commonly employed in cosmetics advertising, often begins with the very name of the product:

Biotherm Skin Energetic Serum

Biotherm Biosource

Chanel Ultra Correction Line Repair

Clinique 3 steps

Elizabeth Arden Ceramide Gold Ultra Restorative

Estée Lauder Resilience Lift Extreme

Lancaster Differently Nutri-Dermo Skin

Lancôme Rénergie Morpholift R.A.R.E. ${ }^{\text {TM }}$

Lierac Phytolastil

L'Oreal Derma Genèse

Vichy Aqualia Thermal

Vichy Normaderm

A closer examination of two versions - English and Portuguese - of an advert for a Lancôme mascara may help clarify this point and offer further issues for analysis. The product is called Hypnose Doll Eyes, a name that is both very descriptive and associative, and that may pose some language obstacles. Though the expression might be recognised by a significant number of potential consumers, especially if aided by the visuals, which are rather self-evident, the Portuguese advertisement includes an additional explanatory 
On the implications of non-translation in Portuguese advertising: names in cosmetic products as a case in point

sentence, so as to make sure the product function or objective is well understood, especially if we take into account that this expression is not part of the habitual jargon of cosmetic names: "A $1^{\mathrm{a}}$ mascara efeito "pestanas de boneca" ('The $1^{\text {st }}$ mascara to give a doll lash effect').

The marketing approach used in Portuguese advertising is not adopted in all countries and is definitely different from that encountered in English advertising. Commonly, product names, including brands other than those belonging to English-speaking countries, are provided in English. It is not at all unusual to find French products that display both French and English names on the packaging. Though there are some brands that use English alone (such as MaxFactor), the most common strategy is to use both English and French, at least in the translation of the third part of the threefold name structure of cosmetics, as it is the one containing the descriptive element:

Clarins - Baume Couleur Lèvres / Colour Quench Lip Balm

Clarins - Doux Exfoliant / Gentle Exfoliator - Lotion de Clarté / Brightening Toner

Bobbi Brown - SPF Tinted Moisturizer 15 / Hydratant Teinté SPF 15

Lancôme - Adaptîve - Fond de Teint Re-Equilibrant en Continu /Continuous Skin-Balancing Makeup

Lancôme - Effacernes Longue Tenue - Soin Teinté Unifiant Anticernes / Long-Lasting Softening Concealer

Lancôme Primordiale Skin Recharge - Soin Renovateur Lissant Visible IP 15 / Visible Smoothing Renewing Moisturiser SPF 15

International brands (from various origins) tend to name their products in English, which seems to confirm that English is used as a tool by internationally-oriented brands, and that though French is traditionally associated with cosmetology, it has lost its dominance over English, which has invaded a previously unchallenged domain. Notwithstanding, the prestige of French language is still patent in French (sounding) names, and in the use of 'Paris' below the brand name, even in the case of brands that have been taken over by big international groups from other countries, as in CLARINS Paris, L'OREAL Paris or LANCÔME Paris:

One might imagine that the popularity of the French language in perfume [and cosmetics] advertising is partly because the French have his- 
torically dominated perfume [and cosmetics] production, but it seems to relate more to a facet of snobbery. France is universally regarded as superior in matters related to fashion, so that an understanding of things French in this domain is a sign of one's social standing. The advertiser flatters the addressee, a strategy which is alleged to be successful in advertising [...]. (Tanaka, 1994, p. 56)

Whichever strategy is used, what seems to be more relevant for the present analysis is that language may become an issue in Portuguese advertising, as often the Portuguese audience will have to look at the copy to fully understand the properties and/or functions of the advertised products. This may have consequences in terms of advertising impact, especially if we consider the very poor attention the copy normally gets from readers, and that pictures, including the depicted packaging, are more instantly grasped by the potential consumer, even though the interpretation of visual material is culture-bound up to a point (Messaris, 1997, pp. 90-93).

\section{Factors and implications of non-translation in cosmetic products' names}

Previously, we have anticipated a number of factors and effects associated to the use of names of cosmetics in other languages than Portuguese, namely English and French, especially in the context of advertising. This section will attempt to provide a more comprehensive analysis, as, like with most marketing options, the factors contributing to certain strategies are often complex and manifold.

As far as motivating reasons are concerned, it is possible to single out the most pervasive:

a) Economic reasons: standardization implies lower marketing and advertising costs;

b) Brand consistency: maintaining the same name means that the band and product become widely recognised with more or less consensual connotations (see, for example, Belch \& Belch, 2004, p. 669, Yeshin, 2006, p. 422, Wells et al, 1998, p. 682);

c) Country-of-origin effect (see Mueller, 1996, p.31): associations between languages and countries benefit from maintaining names untranslated; in this case, language becomes a key strategic marketing element. 
Therefore, we may expect such names to allude to trendiness, chic, expertise, among other values associated with the cultures at stake. In the case of names in English, however, this is not always the case, as many brands from non-English-speaking countries adopt English names. Cosmetics products and adverts, as the above examples show, repeatedly include product names in English (even in parallel with other names), which is seems to stress the international charisma of the product rather than 'made in' effect, has Piller has demonstrated in various studies dedicated to language contact and multilingualism in advertising (2003, p.175): 'Internationally, English has become a general symbol of modernity, progress, and globalization'.

d) Imported product effect: closely associated with the 'international' product effect, it seems clear that international brands enjoy prestige in the target country. This seems to be a commonly acknowledged factor in the use of English in advertising. The study of the Asian market mentioned above regards this as an overriding factor, and it has also been pinpointed in studies of multilingual advertising in different countries. An example of this is Piller's analysis of multilingual adverts in Germany, where the author states that 'In the vast majority of advertisements that use English, it is the language of international communication and not the language of a particular national community (2003, p.164).

e) Favourable cultural environment: names and other cases of more blatant foreignness in advertising seem to indicate a cultural environment that welcomes interference from other languages in advertising. It is also implied by this vector the fact the audience is expected to understand the terms used. In the case of cosmetology, in the scarcity of Portuguese products of the type, the audience is likely to be even more used to the jargon (both in French and in English), as most advertisements (and products) come from international foreign) brands.

Piller adds another relevant effect to the use of foreign languages that could easily be of paramount importance in the case of cosmetics product names: prolonged attention: 'A general advantage of the use of a foreign language is that it impedes automatic processing and thereby arrests the attention of recipients for a longer timespan than monolingual native-language adverti- 
sements would' (2003, p.163). While it is not certain that this is a deliberate goal of advertisers' strategy, it is, at least, a favourable outcome.

The possible effects that may be elicited from the use of these strategies could be, however, more complex and multidimensional. Authors such as Yeshin point out a number of factors that can affect international advertising, and which can, therefore, make a difference to the outcome of the campaign: after language (the paramount vector in this process), others can be put forward, such as differences in culture and tradition, which include the audiences' perception, motivation, learning and memory, meaning, age, self-concept, group influence, social class, sex roles, decision making models, purchase patterns, motivational factors and aspirations, loyalty and purchasing environment, post-purchase expectations and standards of living (2006, p.423).

Other authors, such as Wells et al dwell on the specific difficulties concerning international advertising, referring to, in the first place - as would be expected - to considerations relating to customs and culture, closely followed by a mention of marketing imperialism, which is intimately associated with the issue of global brands. Even more importantly within the scope of the present work, they also foreground the importance of emotions felt by the receiving end of this process towards the 'foreign' goods that are being advertised, such as inertia, resistance, rejection and politics in general (1998, pp. 689-692). For the specific purposes of this article, the following effects can be singled out:

a) Intelligibility: this seems to be one of the most relevant points to be considered. It is indisputable that advertisers count on the fact that many of the terms used in names are understood by the audience, and that the use of such words in other languages may even raise new connotations, thus enriching the advertising message, as Cook explains, 'simply by attracting the extra connotations of the culture of which they are an index' (1992, p. 107). Furthermore, the hegemonic spread of Englishspeaking cultures and the fact that French originates from Latin, thus presenting many similarities with the Portuguese language, ensures a desirable degree of intelligibility. Besides, these products are normally created to be marketed internationally, which means that names are taken into careful consideration so as to evoke positive associations in 
On the implications of non-translation in Portuguese advertising: names in cosmetic products as a case in point

as many cultures as possible. Nonetheless, advertisers should count on some meaning loss, as well. It is hardly surprising that a lot of relevant information contained in product names will be overlooked, or lost 'in non-translation', and only compensated if readers take the trouble to read the advertising copy, which is rather unlikely.

b) Impact: as far as the advertising effects are concerned, the above paragraph points to some relevant aspects. If, on the one hand, advertisers can count on a collateral encouraging effect, such as 'country-of-origin' associations, among others, they should also take into account the loss of impact of certain advertisements that rely mostly on packaging information and pictures, as well the eventual need for completing the visual cues provided.

c) Cultural implications: the implications of such strategies may go well beyond the factors just discussed. On the one hand, they pose translation issues, namely those concerning the norms that prevail in the target culture and which govern translation procedures. On the other hand, foreignness leads to a re-evaluation of power relations in international advertising, namely the spread of influence of dominant cultures over less powerful ones, as well as to the way we perceive ourselves and the Other. Names seem to be only the tip of the iceberg, as, if we look more deeply into it, Portuguese advertising discourse is colonised by foreign terminology.

As we may see, these factors and implications raise several issues, not only those directly connected with marketing and business considerations, but also those concerned with cultural dimensions. Indeed, what seems to favour the adoption of standardized global approaches is the cultural environment: the audience's receptivity to interference. In the Portuguese case, as foreignness often extends to other parts of the advertisement, we may regard nontranslation as part of the translational norms concerning advertising texts. Indeed multilingual adverts are common, not only but also in cosmetics adverts. This trend does not seem peculiar of the Portuguese advertising landscape, as some of the studies mentioned in this article reveal (Piller, 2003 and 2006; Yeshin, 2006; Chang, 2008), as they point to identical circumstances in different countries, but it does play a significant role in Portuguese advertising, which displays different forms of presenting hybridity: through product name, 
through copy in other languages (namely English), through mixed-language adverts, and through parallel translation.

\section{Final remarks}

This short incursion into cosmetics names in advertising has just only unveiled a much wider issue concerning translation of international advertising, but it has nonetheless approached relevant issues within this area. It has looked into the complexity involving product naming, concentrating on the specificity of cosmetic names, which pose peculiar questions due to their tripartite structure and character of names. The latter analysis served mostly to demonstrate the implications that leaving names - and cosmetics' names, in particular - untranslated may originate and that such marketing option, despite being motivated by rational factors, could have multifarious effects in audience reception, and hence response.

This discussion can be taken even further, as we have seen, to issues related to the cultural international and national environment, and thus to norms governing translational practices and to the circumstances that underlie such practices. It seems that the translation strategies adopted by marketers do reflect conformity with the source culture, in addition to the commercial/economic motives, based on advertisers' belief in the potential benefits they may draw from the prestige and influence of a powerful culture in the receiving system. This argument can point to a series of even more complex reflections, including power relations between languages and cultures and their perpetuation and/or mirroring by advertising discourse.

\section{Bibliography}

Belch, G. \& Belch, M. (2004). Advertising and Promotion: An integrated marketing communication perspective. New York: McGraw-Hill.

Birkner, C. (2001). What's in a Name? Naming a new product is more than just a creative exercise. Marketing News, 45(4).

Chang, C. (2008). The Effectiveness of Using a Global Look in an Asian Market. Journal of Advertising Research. June: 199-214.

Cook, G. (1992). The Discourse of Advertising. London and New York: Routledge. 
On the implications of non-translation in Portuguese advertising: names in cosmetic products as a case in point

Dyer, G. (1982). Advertising as Communication. London and New York: Routledge.

Goossens, L. (1985). What's in an Advertising name?. In G. Debusscher \& J.-P. Van Noppen (Ed.) Communiquer et Traduire: Hommages à Jean Dierickx (pp. 95-102). Bruxelles: Éditions de L’Université de Bruxelles.

Guidère, M. (2000). Publicité et Traduction. Paris: L'Harmattan.

Hammel, S. (1997). What's in a name? For the pros, big bucks. News and World Report, 123(14).

Merskin, D. (2007). Truly Toffee and Raisin Hell: A Textual Analysis of Lipstick Names. Sex Roles 56: 591-600.

Messaris, P. (1997). Visual Persuasion: The Role of Images in Advertising. Thousand Oaks: Sage.

Mueller, B. (1996). International Advertising: Communicating Across Cultures. Belmont CA: Wadsworth Publishing Company.

Piller, I. (2003). Advertising as a Site of Language Contact. Annual Review of Applied Linguistics, 23: 170-183.

Piller, I. (2006). Identity constructions in multilingual advertising. Language in Society, 30: 153-186.

Tanaka, K. (1994). Advertising Language: A pragmatic approach to advertisements in Britain and Japan. London: Routledge.

Wells, W.; Burnett, J. \& Moriarty, S. (1998). Advertising : Principles \& practice. London, Sidney, Toronto: Prentice-Hall International Editions.

Yeshin, T. (2006). Advertising. London: Thompson. 